\title{
KARAKTERISTIK FISIKOKIMIA EKSIPIEN TABLET DARI PATI SUKUN (ARTOCARPUS COMMUNIS)
}

\author{
Gayuk Kalih Prasesti*, Mirhansyah Ardana, Rolan Rusli \\ Laboratorium Penelitian dan Pengembangan FARMAKA TROPIS \\ Fakultas Farmasi Universitas Mulawarman, Samarinda, Kalimantan Timur \\ *email: Gayuk_kalihprasesti@yahoo.com
}

\begin{abstract}
Purpose of this research were to know the difference and physicochemical characteristics of starch from breadfruits of one (MH1) and two (MH2) month of harvest. Starch of breadfruit were obtained by decantation and drying. Evaluation of the physicochemical characteristics of starch powder were measured contents of amylose and amylopectin, organoleptic, $\mathrm{pH}$, shape, compressibility index, density and flow rate. Rendement of breadfruits starch was 10.62\% (MH1) and 12.29\% (MH2). Amylose and amylopectin contents were $4.087 \%$ and $81.637 \%$ (MH1) and $10.213 \%$ and $85.673 \%$ (MH2). pHof starch (MH1 and MH2) was 3.99. In microscopic, starch granule has hilus. Organoleptic of MH1 starch were odorless, tasteless, white and soft powder whereas MH2 starch has special smell of breadfruit, tasteless, white brownish, and rough powder. Compressibility index of breadfruits starch were $39.6 \%$ (MH1) and 38.3 (MH2). Value of bulk density $(\mathrm{g} / \mathrm{mL})$ were $0.34(\mathrm{MH} 1)$ and $0.42(\mathrm{MH} 2)$, whilst value of tapped density $(\mathrm{g} / \mathrm{mL})$ were 0.57 (MH1) and 0.68 (MH2). The both of starch have no flow rate and corner of rest. Analysis independent sample t-test $(\alpha=0.05)$ showed that the content of amylopectin, $\mathrm{pH}$, and compressibility index has not significant difference, whilst content of amylose, bulk density and tapped density has a significant difference.
\end{abstract}

Keywords: breadfruits starch, characteristics, excipients, physicochemical

\begin{abstract}
ABSTRAK
Penelitian ini bertujuan untuk melihat perbedaan rendemen dan karakteristik fisikokimia pati buah sukun yang berasal dari buah sukun masa panen 1 bulan (MP1) dan 2 bulan (MP2). Pati sukun diperoleh dengan cara dekantasi dan pengeringan. Evaluasi karakteristik fisikokimia serbuk pati meliputi pengukuran kadar amilosa dan amilopektin, organoleptis, $\mathrm{pH}$, bentuk, indeks kompresibilitas, densitas dan laju alir. Rendemen pati sukun yang diperoleh adalah 10,62\% (MP1) dan 12,29\% (MP2). Kadar amilosa dan amilopektin adalah 4,087\% dan 81,637\% (MP1) serta 10,213\% dan 85,673\% (MP2). Nilai pH pati untuk MP1 dan MP2 sama yaitu 3,99. Granula pati memiliki hilus berdasarkan pengamatan mikroskopik. Organoleptis pati MP1 adalah tidak berbau, tidak berasa berwarna putih dan memiliki bentuk serbuk halus sedangkan pati MP2 adalah berbau khas buah sukun, tidak berasa, putih kecoklatan, dan bentuk serbuk agak kasar. Indeks kompresibilitas pati sukun adalah 65,77\% (MP1) dan 62,09\% (MP2). Nilai bulk density (g/mL) sebesar 0,34 (MP1) dan 0,42 (MP2), sedangkan nilai tapped density (g/mL) sebesar 0,57 (MP1) dan 0,68 (MP2). Kedua pati tidak memiliki laju alir maupun sudut istirahat. Analisis independent sample t-test $(\alpha=0,05)$ menunjukkan bahwa kadar amilopektin, $\mathrm{pH}$, dan indeks kompresibilitas tidak memiliki perbedaan yang signifikan, sedangkan kadar amilosa, bulk density, dan tapped density memiliki perbedaan yang signifikan.
\end{abstract}


Kata kunci: eksipien, karakteristik, fisikokimia, pati sukun

\section{PENDAHULUAN}

Eksipien adalah zat yang digunakan sebagai bahan tambahan atau pendukung dalam suatu formula sediaan, bersifat inert dan tidak mempunyai efek farmakologi. (Anwar, 2012).

Peranan eksipien sangat esensial untuk memastikan proses pembuatan berhasil dan formula yang dihasilkan memiliki kualitas yang terjamin. Ketepatan pemilihan eksipien dan konsentrasi relatifnya pada formula adalah faktor penting dalam perkembangan dan keberhasilan produk (Gad, 2008).

Pemanfaatan bahan alam sebagai bahan baku pembuatan eksipien dapat dilakukan untuk meningkatkan variasi eksipien berbahan dasar alami. Pati merupakan eksipien multifungsi yang dapat digunakan sebagai disintegrator, pengikat maupun pengisi. Pati dapat diperoleh dari berbagai macam sumber daya alam yang memiliki kandungan karbohidrat yang tinggi, salah satunya adalah buah sukun.

Oleh karena itu, perlunya studi terkait dengan karakterisasi dari pati yang berasal dari buah sukun tersebut yang akan dimanfaatkan sebagai sumber eksipien berbahan dasar alam dengan melihat perbedaan karakteristik fisikokimia dari pati yang berasal dari buah sukun masa panen 1 bulan dan 2 bulan.

\section{METODE PENELITIAN}

\section{Bahan}

Bahan yang digunakan adalah buah sukun masa panen 1 bulan dan 2 bulan, aquadest, kain saring, $\mathrm{HCl}$, Butanol, Metanol dan kertas grafik milimeter.

\section{Peralatan}

Peralatan yang digunakan adalah blender, oven, ayakan mesh 80, timbangan analitik, hot plate, sentrifuge, tabung sentrifuge, cawan porselin, $\mathrm{pH}$-meter, statif dan klem, corong kaca, mikroskop elektrik, kaca objek dan kaca penutup, seperangkat alat gelas laboratorium.

\section{Prosedur}

\section{Pembuatan Pati Sukun}

Pati sukun diperoleh dari buah sukun masa panen 1 bulan dan 2 bulan menggunakan metode ekstraksi dengan aquadest $1: 1$, dekantasi dan pengeringan selama 7 jam pada $70^{\circ} \mathrm{C}$, pengayakan dilakukan pada ayakan 80 mesh.

\section{Karakterisasi Pati Sukun}

\section{Penentuan Kadar Amilosa dan Kadar Amilopektin}

Berdasarkan penelitian yang dilakukan oleh Albert Teja (2008) penentuan kadar amilosa dan amilopektin dilakukan dengan metode hidrolisis asam menggunakan $\mathrm{HCl}$ $0,1 \mathrm{~N}$ dan butanol, kemudian pemanasan pada $85{ }^{\circ} \mathrm{C}$ selama 35 menit, pendinginan selama 24 jam pada suhu ruang. Kemudian dilakukan sentrifugasi. Setelah disentrifugasi endapan tersebut dikeringkan dan selanjutnya ditimbang untuk mendapatkan kandungan amilosa (\%). Cairan sisa hasil sentrifugasi ditimbang kemudian ditambahkan dengan $200 \mathrm{~mL}$ metanol dan didekantasi untuk mendapatkan kandungan amilopektin. 


\section{Pengamatan Organoleptis}

Pemeriksaan organoleptis pati sukun diamati meliputi bentuk, warna, rasa dan bau.

\section{Penetapan pH}

Nilai $\mathrm{pH}$ diukur dengan menggunakan $\mathrm{pH}$ meter pada suspensi sampel $10 \%$.

\section{Pengukuran Densitas}

Sejumlah serbuk pati dimasukkan ke dalam gelas ukur hingga volume $100 \mathrm{ml}$ dan dicatat berat gelas ukur setelah dan sebelum ditambahkan serbuk pati. Lalu dilakukan pengetukan dan volume pada ketukan ke 500 diukur sebagai volume mampat, lalu dilakukan perhitungan sebagai berikut:

Bulk density $\quad=\frac{\text { bobot serbuk }}{\text { volume serbuk }}$

Tapped density $=\frac{\text { bobot serbuk }}{\text { volume mampat }}$

\section{Penentuan Indeks Kompresibilitas}

Kompresibilitas dihitung menggunakan persamaan:

$\mathrm{I}=\frac{\text { tapped density }- \text { bulk density }}{\text { bulk density }} \times 100 \%$

I adalah indeks kompresibilitas; Syarat indeks kompresibilitas yang baik adalah tidak lebih dari $20 \%$.

\section{Penentuan Laju Alir}

Serbuk pati dimasukkan ke dalam corong uji waktu alir, dicatat waktu alir, tinggi dan diameter serbuk yang keluar dari corong untuk menentukan sudut diamnya. kertas grafik milimeter. Sudut diam antara $20^{\circ}-40^{\circ}$ dan waktu alir sebesar $>10 \mathrm{~g} /$ detik menunjukkan potensial aliran yang baik.

\section{Pengamatan Bentuk Pati}

Pengamatan menggunakan mikroskop elektrik. Sejumlah sampel ditetesi dengan aquadest pada kaca objek, dilakukan pengamatan pada perbesaran 100×.

\section{HASIL DAN PEMBAHASAN}

\section{Rendemen Pati Sukun}

Rendemen pati sukun yang dihasilkan oleh buah sukun dengan masa panen 1 bulan dan 2 bulan ditunjukkan pada tabel 1 .

Tabel 1. Rendemen pati sukun

\begin{tabular}{lllll}
\hline $\begin{array}{l}\text { Pati sukun } \\
\text { (masa panen) }\end{array}$ & Replikasi & $\begin{array}{l}\text { Berat basah } \\
(\mathrm{g})\end{array}$ & $\begin{array}{l}\text { Berat kering } \\
(\mathrm{g})\end{array}$ & Rendemen $(\%)$ \\
\hline 1 bulan & I & 1000 & 123,7 & 12,37 \\
& II & 1000 & 123,3 & 12,33 \\
& III & 1000 & 71.7 & 7,17 \\
\hline Rata-Rata $(\overline{\boldsymbol{x}})$ & & & & 10,62 \\
\hline 2 bulan & I & 1000 & 139,7 & 13,97 \\
& II & 1000 & 111,4 & 11,14 \\
& III & 1000 & 117,7 & 11,77 \\
\hline Rata-Rata $(\overline{\boldsymbol{x}})$ & & & 12,29 \\
\hline
\end{tabular}


Berdasarkan tabel 1 terlihat nilai rata-rata pati sukun dengan buah sukun masa panen 1 bulan adalah 10,62\% dan pati sukun dengan buah sukun masa panen 2 bulan adalah $12,29 \%$. Hasil analisis independent sample t-test, dengan taraf signifikansi 0,05 $(\alpha=0,05)$ menunjukkan bahwa tidak terdapat perbedaan yang signifikan terhadap nilai rendemen antara pati sukun dengan buah sukun masa panen 1 bulan dan 2 bulan. Hal ini berarti bahwa untuk mendapatkan pati sukun dengan jumlah tertentu, dapat dilakukan dengan menggunakan buah sukun yang dikatakan masih muda atau mentah dan tidak perlu menunggu buah sukun hingga berusia tua, hal ini dapat mengoptimalkan dan meningkatkan efesiensi waktu pengerjaan.

\section{Karakterisasi Pati Sukun}

\section{Karakterisasi Kimia}

Karakterisasi kimia pati sukun dengan buah sukun masa panen 1 bulan dan 2 bulan ditunjukkan pada tabel 2 .

Tabel 2. Karakterisasi kimia pati sukun

\begin{tabular}{lcc}
\hline \multirow{2}{*}{ Karakterisasi Kimia } & \multicolumn{2}{c}{ Pati sukun (masa panen ) } \\
\cline { 2 - 3 } & 1 bulan & 2 bulan \\
\hline Kadar amilosa $(\%)$ & 4,087 & 10,213 \\
Kadar amilopektin $(\%)$ & 81,637 & 85,673 \\
pH & 3,99 & 3,99 \\
\hline
\end{tabular}

\section{Kadar Amilosa dan Amilopektin}

Amilosa dapat mempengaruhi proses pengembangan pati dan tingkat kekentalan pati. Amilosa berperan dalam pembentukan gel sedangkan amilopektin membentuk sifat viskoelastis. Semakin besar kadar amilosa, maka semakin kecil kemampuan mengembangnya pati dan kekuatan gel semakin rendah. Peningkatan kadar amilosa mengurangi daya ikat pati dan menurunkan kekuatan gel (Zobel, 1992). Dari tabel 2, terlihat bahwa kadar amilosa baik pada pati sukun dengan buah sukun masa panen 1 bulan dan 2 bulan memilki kadar amilosa yang lebih rendah daripada kadar amilopektin. Tinginya kadar amilopektin pada pati sukun menunjukkan bahwa pati sukun ini memiliki potensi sebagai pengikat jika digunakan sebagai eksipien pada proses pembuatan tablet. Hasil analisis independent sample t-test, dengan taraf signifikansi $0,05 \quad(\alpha=0,05)$ menunjukkan bahwa tidak terdapat perbedaan yang signifikan terhadap persen kadar amilosa dan amilopektin antara pati sukun dengan buah sukun masa panen 1 bulan dan 2 bulan.

pH

Berdasarkan tabel 2, terlihat bahwa derajat keasaman antara suspensi pati sukun dengan buah sukun masa panen 1 bulan dan 2 bulan memiliki nilai yang sama yaitu 3,99. Hal ini menunjukkan tidak terdapat perbedaan di antara kedua pati terhadap nilai $\mathrm{pH}$.

\section{Karakterisasi Fisika}

Parameter pada karakterisasi fisika ditunjukkan pada tabel 3. 
Tabel 3. Karakterisasi fisika pati sukun

\begin{tabular}{lll}
\hline \multirow{2}{*}{ Karakterisasi Fisika } & \multicolumn{2}{c}{ Pati sukun (masa panen ) } \\
\cline { 2 - 3 } & \multicolumn{1}{c}{ 2 bulan } & \multicolumn{1}{c}{ 2 bulan } \\
\hline Indeks kompresibilitas $(\%)$ & 65,77 & 62,09 \\
Bulk density $(\mathrm{g} / \mathrm{mL})$ & 0,34 & (praktis tidak mengalir) \\
Tapped density $(\mathrm{g} / \mathrm{mL})$ & 0,57 & 0,42 \\
Organoleptis & Putih, serbuk halus, tidak & Putih kecoklatan, serbuk \\
& berbau, tidak berasa & agak kasar, bau khas buah \\
& & sukun, tidak berasa \\
Laju Alir & Tidak memiliki laju alir \& & Tidak memiliki laju alir \& \\
& sudut istirahat & sudut istirahat \\
\hline
\end{tabular}

\section{Indeks Kompresibilitas}

Indeks kompresibilitas merupakan parameter kemampuan serbuk untuk dapat dimampatkan. Indeks kompresibilitas ditentukan dari dua variabel densitas yakni bulk density dan tapped density. Indeks kompresibilitas yang dimiliki oleh pati sukun dengan buah sukun masa panen 1 bulan adalah $65,77 \%$ sedangkan pati sukun dengan buah sukun masa panen 2 bulan memiliki indeks kompresibilitas sebesar 62,09\%. Hasil analisis independent sample t-test, dengan taraf signifikansi $0,05(\alpha=0,05)$ menunjukkan bahwa tidak terdapat perbedaan yang signifikan terhadap nilai indeks kompresibilitas antara pati sukun dengan buah sukun masa panen 1 bulan dan 2 bulan. Dari hasil indeks kompresibilitas kedua pati, menunjukkan sifat aliran serbuk pati yakni praktis tidak mengalir, karena nilai indeks $>40$.

\section{Densitas}

Pati sukun dengan buah sukun masa panen 1 bulan memiliki bulk density sebesar $0,34 \mathrm{~g} / \mathrm{mL}$ sedangkan pati sukun dengan buah sukun masa panen 2 bulan memiliki bulk density sebesar $0,42 \mathrm{~g} / \mathrm{mL}$. Nilai tapped density diperoleh sebesar $0,57 \mathrm{~g} / \mathrm{mL}$ dan 0,68 $\mathrm{g} / \mathrm{mL}$ untuk masing-masing pati sukun 1 bulan dan 2 bulan. Hasil analisis independent sample t-test, dengan taraf signifikansi $0,05(\alpha=0,05)$ menunjukkan bahwa terdapat perbedaan yang signifikan terhadap nilai bulk density dan tapped density antara pati sukun dengan buah sukun masa panen 1 bulan dan 2 bulan.

Partikel dengan ukuran lebih kecil akan membentuk massa dengan kerapatan lebih besar, akibat pengurangan rongga-rongga antar partikel. Selain itu, bentuk partikel juga mempengaruhi bulk density dimana partikel-partikel dengan bentuk irregular cenderung memiliki porositas besar diakibatkan rongga-rongga antar partikel yang terisi oleh udara sehingga bulk density lebih kecil (Gordon, 1989). Ditinjau dari nilai bulk density dan tapped density, pati sukun dengan buah sukun masa panen 2 bulan memiliki porositas yang lebih kecil daripada pati sukun dengan buah sukun masa panen 1 bulan, oleh karena itu jika diinginkan suatu formula tablet yang memiliki friabilitas dan friksibilitas baik, pati sukun yang digunakan sebaiknya yang berasal dari buah sukun masa panen 2 bulan, karena serbuk pati yang dihasilkan memiliki rongga-rongga udara yang lebih kecil daripada pati sukun dengan buah sukun masa panen 1 bulan.

\section{Organoleptis}

Pengujian organoleptis pati sukun dilakukan meliputi warna, bentuk, bau dan rasa. Pada pati sukun dengan buah sukun masa panen 1 bulan memiliki warna putih, berupa serbuk halus, tidak berbau dan tidak berasa sedangkan pati sukun dengan buah sukun masa panen 2 bulan memiliki warna putih kecoklatan, serbuk agak kasar daripada pati sukun 1 
bulan, bau khas buah sukun dan tidak berasa. Warna yang berbeda dapat dipengaruhi dari bahan dasar yang digunakan, buah sukun dengan masa panen 2 bulan memiliki warna yang lebih kuning daripada buah sukun masa panen 1 bulan yang lebih putih, oleh karena itu warna pati sukun yang dihasilkan juga berbeda. Demikian pula pada bau pati yang dihasilkan juga dipengaruhi oleh bau awal dari buah sukun, pada masa panen 2 bulan memiliki bau yang lebih kuat daripada buah sukun dengan masa panen 1 bulan.

\section{Laju Alir}

Kedua pati sukun baik dengan buah sukun masa panen 1 bulan dan masa panen 2 bulan tidak memiliki laju alir maupun sudut istirahat. Hal ini dapat dikarenakan serbuk memiliki kerapatan yang tinggi sehingga daya alirnya tidak baik yang mengakibatkan sudut diamnya tidak dapat diketahui.

\section{Bentuk Partikel}

Hasil pengamatan bentuk partikel menggunakan mikroskop elektrik dengan perbesaran $100 \times$ ditunjukkan pada gambar 1 dan 2 .

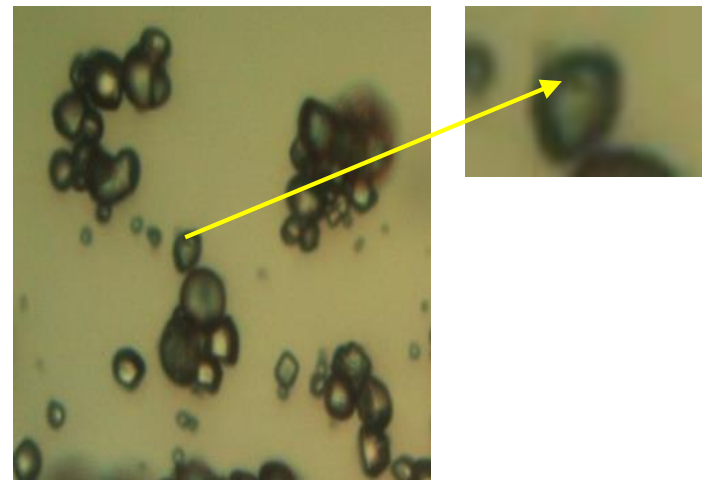

Gambar 1. Mikroskopik pati sukun masa panen 1 bulan

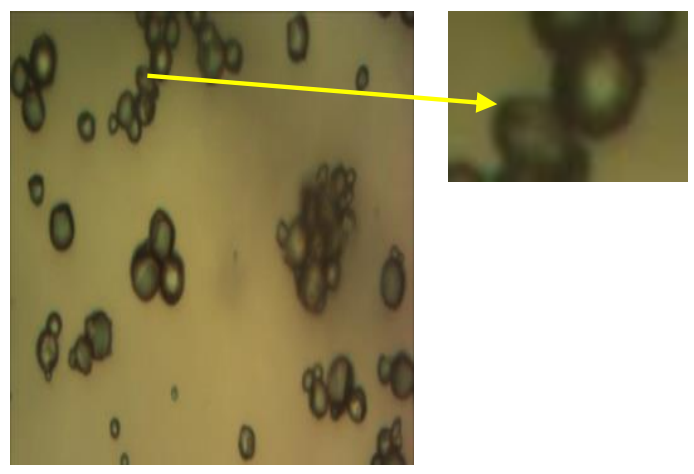

Gambar 2. Mikroskopik pati sukun masa panen 2 bulan

Berdasarkan gambar 2 penampang mikroskopik pati sukun di atas, terlihat adanya hilus pada granula pati, baik pada pati sukun dengan buah sukun masa panen 1 bulan dan 2 bulan. Hilus merupakan titik permulaan terbentuknya pati. Pati sukun ini termasuk ke dalam jenis amilum eksentris, karena memiliki hilus yang terletak di pinggir (Mulyani, 2006). 


\section{KESIMPULAN}

Berdasarkan hasil penelitian yang diperoleh, dapat disimpulkan bahwa:

1. Rendemen pati sukun dengan buah sukun masa panen 1 bulan adalah $10,62 \%$ sedangkan pada masa panen 2 bulan adalah $12,29 \%$, dan terlihat perbedaan yang tidak signifikan antar keduanya.

2. Karakterisasi kimia pada parameter kadar amilosa dan amilopektin serta pH tidak mengalami perbedaan yang signifikan. Karakterisasi fisika pada parameter indeks kompresibilitas tidak memiliki perbedaan yang signifikan sedangkan pada parameter bulk density dan tapped density memiliki perbedaan yang signifikan.

3. Pati sukun dengan buah sukun masa panen 1 bulan dan 2 bulan tidak memiliki laju alir dan sudut istirahat.

4. Organoleptis pati sukun dengan buah sukun masa panen 1 bulan adalah tidak berbau, tidak berasa berwarna putih dan memiliki bentuk serbuk halus sedangkan pati sukun 2 bulan adalah berbau khas buah sukun, tidak berasa, putih kecoklatan, dan bentuk serbuk agak kasar.

5. Jenis amilum pati sukun adalah amilum eksentris.

\section{DAFTAR PUSTAKA}

1. Anwar, Effionora. 2012. Eksipien dalam Sediaan Farmasi Karakterisasi dan Aplikasi. Penerbit Dian Rakyat: Jakarta.

2. Gad, Shayne C. 2008. Pharmaceutical Manufacturing Handbook Production and Processes. A John Wiley \& Sons Inc Hoboken: New Jersey.

3. Teja, Albert. 2008. Karakteristik Pati Sagu dengan Metode Modifikasi Asetilasi dan Cross-Linking. Jurnal Teknik Kimia Indonesia. 7. (3). 836-843.

4. Zobel, H.F. Starch: Source, Production dan Properties. Dalam: Schenck , F.W dan Hebeel, R.E. Starch Hydrolysis Product. New York: VCH Publisher ,Inc., 1992: 23 29.

5. Gordon, R E., Rosanske, T W., Fonner, D E., Anderson, N R dan Banker, G S. Granulation technology and tablet characterization. Dalam: Lieberman, $H$ A., Lachman, L dan Schwartz, J B. Pharmaceutical dosage forms: Tablets. Vol 2. 2nd Ed. New York: Marcel Dekker, Inc., 1989. Hal: 317 - 338.

6. Mulyani, Sri. 2006. Anatomi Tumbuhan.Kanisius: Yogyakarta. 